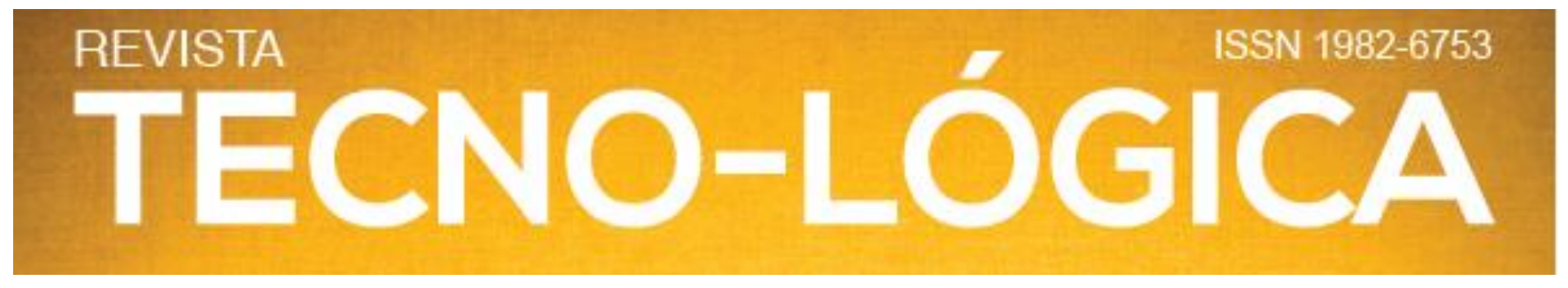

\title{
AVALIAÇÃo DA SUPRESSÃO DA VEGETAÇÃO NATIVA NO MUNICÍPIO DE CONDOR, RIO GRANDE DO SUL
}

\author{
Eduardo Santos Erthal ${ }^{1 *}$, Gracieli Manfrin da Silva Erthal ${ }^{2}$, Gerson Azulim Muller ${ }^{3}$ \\ 1 Pós-graduação em Biodiversidade e Conservação, Instituto Federal Farroupilha, 98280-000, Panambi, Brasil. \\ 2 Secretaria Estadual da Agricultura, Pecuária e Desenvolvimento Rural - SEAPDR, 98005-129, Cruz Alta, Brasil \\ 3 Pós-graduação em Biodiversidade e Conservação, Instituto Federal Farroupilha, 98280-000, Panambi, Brasil
}

*E-mail: erthal1991@gmail.com

Recebido em: 29/04/2021

Aceito em: 24/06/2021

DOI: 10.17058/tecnolog.v25i2.16553

\begin{abstract}
RESUMO
Intervenções humanas sobre áreas de mata nativa, em áreas urbanas e em áreas rurais são cada vez mais frequentes. Levando em conta o tamanho da intervenção, os impactos ambientais associados poderão causar grandes prejuízos ao meio biótico e abiótico. A Lei Federal $\mathrm{n}^{\circ}$ 6.938/81, que estabelece a Política Nacional de Meio Ambiente, traz como um de seus instrumentos mais importantes, o licenciamento ambiental. Dentre os diversos tipos de licenciamentos, há o licenciamento florestal que é o instrumento da política florestal do Estado, compreendendo serviços prestados pelo órgão ambiental estadual ou municipal competente. A Resolução CONSEMA 372/2018 define que para as atividades de impacto local o órgão responsável pelo licenciamento é o município. O Rio Grande do Sul conta oficialmente com 804 espécies da sua flora nativa ameaçadas de extinção. Deste modo percebe-se a importância de identificar quais são as espécies da flora que estão sofrendo maior supressão, considerando o licenciamento florestal no âmbito do município de Condor-RS, assim como identificar aspectos referentes ao local de manejo (urbano ou rural), proposta de reposição florestal, e formação dos responsáveis técnicos responsáveis pelo projeto de licenciamento ambiental. Os dados foram extraídos das licenças florestais emitidas pelo órgão ambiental licenciador do município de Condor-RS, através de pesquisa e análise dos alvarás florestais deferidos nos últimos 5 anos (2015 a 2019). O Estudo demonstrou uma intensa exploração de poucas famílias, sendo as famílias Fabaceae e Lauraceae as mais suprimidas. O maior número de indivíduos suprimidos pertence à espécie Araucaria angustifolia.
\end{abstract}

Palavras-chave: Desmatamento. Araucaria angustifólia. Licenciamento Florestal. Gestão Ambiental

\section{Introdução}

Segundo Moraes [1], nas regiões Tropicais do mundo encontra-se a maior diversidade biológica do planeta Terra, nomeadamente no Brasil, a Mata Atlântica é a segunda maior floresta tropical úmida, ficando atrás somente da Floresta Amazônica. Considerando seu alto grau de endemismo e grande biodiversidade, o Domínio Mata Atlântica é protegido através da Lei Federal 11.428/2006, que contempla o uso sustentável dos recursos naturais, sua preservação e reestabelecimento de áreas degradadas, no intuito de manter essas áreas como local estratégico de conservação.

O estado do Rio Grande do Sul possui $282.062 \mathrm{~km}^{2}$ constituído de dois grandes domínios, a Mata Atlântica e o Pampa. De acordo com Chiappeti [2], no estado, as florestas nativas da
Mata Atlântica ocupavam 39,7\% do território, restando hoje menos de 3\% das formações originais, correspondendo a 7.496 $\mathrm{km}^{2}$. Segundo o Plano Municipal de Desenvolvimento Rural de Condor-RS [3], o município situa-se na região do Planalto Médio do Estado do Rio Grande do Sul, e pertence ao Domínio Mata Atlântica, integrando a região fitoecológica da Floresta Estacional Semidicidual. O município possui uma área de $465 \mathrm{Km}^{2}$, sendo que originalmente era coberto por floresta nativa e algumas regiões com campo nativo. Atualmente as áreas de floresta estão reduzidas a menos de $20 \%$ de seu território.

Condor é um município eminentemente agrícola, tendo como suas principais atividades econômicas as plantações de soja, trigo e milho, sendo emergente na bacia leiteira e gado de corte. Além disso, o setor industrial é formado por microempresas e agroindústrias. De acordo com o Plano Municipal de 


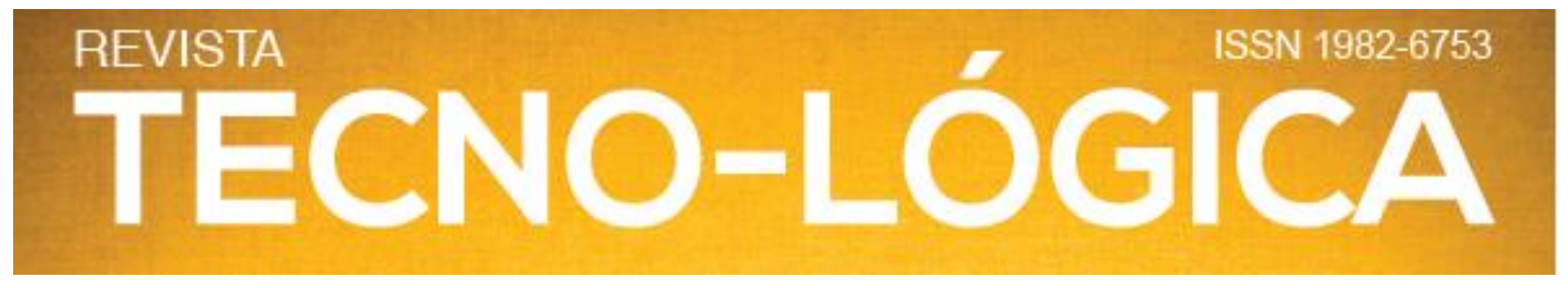

Desenvolvimento Rural do município [3], com a evolução das atividades antrópicas, com consequente redução de fragmentos de vegetação nativa, espécies da flora que antes possuíam condições adequadas para manutenção e sobrevivência, atualmente encontram-se reduzidas, dificultando e até mesmo impossibilitando a capacidade de manutenção da espécie no local, diminuindo desse modo a diversidade de espécies.

A intervenção humana sobre áreas de mata nativa, em áreas urbanas e em áreas rurais é cada vez mais frequente. A operação nessas áreas devido a instalação de empreendimentos, como loteamentos de terrenos e atividades agrossilvipastoris, demandam a ocupação e transformação da superfície do terreno, havendo uma mudança de seu estado natural. Levando em conta o tamanho da intervenção, os impactos ambientais associados poderão causar grandes prejuízos ao meio biótico e abiótico.

A Lei Federal $n^{\circ}$ 6.938/81 estabelece a Política Nacional de Meio Ambiente a qual traz como um de seus instrumentos mais importantes, o licenciamento ambiental. Gurgel Jr. [4] descreve que o licenciamento ambiental é uma ferramenta imprescindível na gestão ambiental, sendo que contribui para informações acerca dos impactos ambientais e garante as medidas mitigadoras e compensatórias frente ao empreendedor, isso se corretamente aplicado pelos órgãos ambientais municipais, estaduais e federais.

Dentre os diversos tipos de licenciamentos, há o licenciamento florestal que, segundo a Secretaria do Meio Ambiente e Infraestrutura (SEMA) [5], é o instrumento da política florestal do Estado, compreendendo serviços prestados pelo órgão ambiental estadual ou municipal competente. Os órgãos ambientais visam a regularização e fiscalização dos diferentes tipos de manejo de espécies florestais nativas e devidas compensações florestais.

A Resolução CONSEMA 372/2018 [6] define que para as atividades de impacto local o órgão responsável pelo licenciamento é o município, desde que os respectivos municípios possuam convênio de delegação de competência da gestão da Mata Atlântica, caso contrário, o licenciamento deve ser realizado pelo órgão ambiental estadual competente. Em seu artigo $5^{\circ}$, parágrafo $2^{\circ}$, está descrito que os empreendimentos e atividades de impacto local que envolvam necessidade de supressão de vegetação em formações florestais nativas e ecossistemas associados no Domínio Mata Atlântica serão licenciados pelos órgãos ambientais municipais competentes.

Assim o proprietário/empreendedor do imóvel rural ou urbano deverá requerer o licenciamento florestal em procedimento administrativo junto ao órgão ambiental competente. Consequentemente os órgãos ambientais municipais comportam uma infinidade de dados locais, dados que podem ser compilados, tratados e transformados em informações importantes para gestão ambiental do município e do estado.
De acordo com a Secretaria Estadual do Meio Ambiente [7], em lista homologada em 2014, o Rio Grande do Sul conta oficialmente com 804 espécies da sua flora nativa ameaçadas de extinção, enquadradas em três categorias de ameaça: vulnerável, em perigo e criticamente em perigo. A reavaliação da lista de espécies da flora ameaçadas em 2014, que tinha como versão anterior a elaborada em 2002, garante uma maior qualidade para a gestão ambiental do estado, apresentando as fragilidades do meio ambiente e, ao mesmo tempo, a necessidade de políticas públicas para conservar, através do licenciamento, a flora nativa estadual.

Deste modo, conhecendo as espécies da flora nativa do Rio Grande do Sul que se encontram ameaçadas de extinção, percebese a importância de identificar quais são as espécies da flora que estão sofrendo maior supressão, e se estas encontram-se em situação de ameaça de extinção, considerando o licenciamento florestal no âmbito do município de Condor-RS, um município conhecido por sua forte atividade econômica no setor agrícola e também industrial.

O presente estudo tem por objetivo avaliar, por meio da análise dos dados sobre o licenciamento ambiental do município de Condor-RS, aspectos relacionados à supressão de mata nativa.

\section{Metodologia}

Os dados foram extraídos das licenças florestais emitidas pelo órgão ambiental licenciador do município de Condor-RS, por meio de pesquisa e análise dos alvarás florestais deferidos entre os anos de 2015 à 2019 que se encontram disponíveis para consulta no SISLAM (Sistema de Licenciamento Ambiental), utilizado pelo Departamento do Meio Ambiente do município para encaminhamento e solicitação de licenças ambientais.

A partir da consulta aos alvarás foi possível extrair informações como espécies da flora manejadas, elencando quais espécies são mais suprimidas, quantidade de indivíduos suprimidos, local de manejo (urbano ou rural), proposta de reposição florestal, e formação dos responsáveis técnicos responsáveis pelo projeto de licenciamento ambiental. Os dados foram tratados pela estatística descritiva para fins de apresentação objetiva dos dados extraídos. As espécies foram avaliadas quanto ao seu grau de risco no acervo da Flora Digital do Rio Grande do Sul e de Santa Catarina [8] e na lista vermelha do Centro Nacional de Conservação da Flora [9].

Portanto, conforme delineamento da pesquisa, pode-se classificar esta como descritiva documental. De acordo com Gil [10] a pesquisa documental vale-se de materiais que não receberam nenhum tratamento analítico, ou que ainda podem ser reelaborados de acordo com os objetos da pesquisa, como os documentos conservados em arquivos de órgãos públicos. O autor ainda destaca que as pesquisas elaboradas com base em 


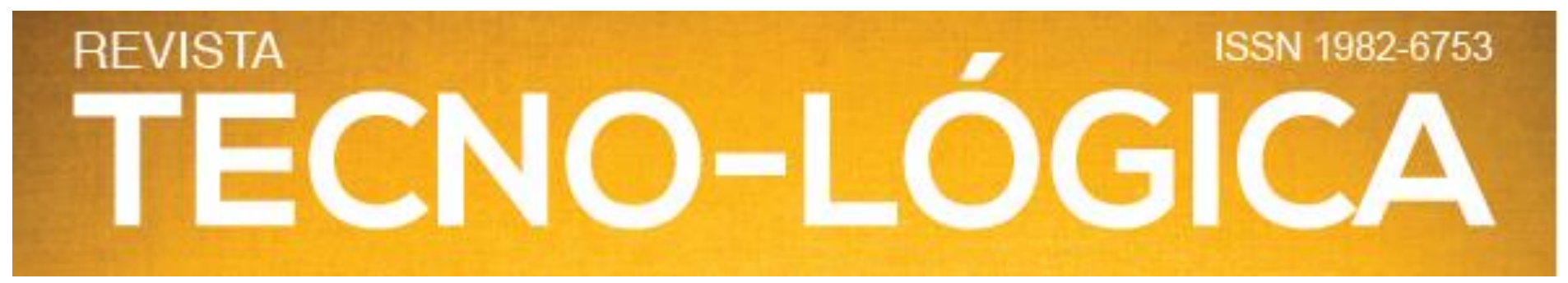

documentos são importantes não porque respondem definitivamente a um problema, mas porque proporcionam melhor visão desse problema ou, então, hipóteses que conduzem a sua verificação por outros meios

\section{Resultados e discussões}

O órgão ambiental licenciador do município de CondorRS, através do sistema SISLAM, licencia os alvarás de serviços florestais, os quais são divididos por atividades distintas. A plataforma conta com 42 atividades cadastradas com um número de identificação (CODRAM - Código de Ramo). Dessas, 13 foram indicadas nos alvarás emitidos no período avaliado com seus respectivos CODRAM's e descrição (Tabela 1).

Dentre as 13 atividades descritas, destacam-se duas como mais frequentes, a 05a (Corte de árvores nativas comprovadamente plantadas em propriedades rurais com área de até 25 hectares) contabilizando 15 alvarás e a 01 b (Supressão de vegetação nativa em estágio médio de regeneração natural em propriedades com área de até 25,0 hectares) com 15 alvarás.

Conforme consta em formulário para requerimento de licença da atividade 05a, disponibilizado no SISLAM, é exigido laudo técnico de avaliação da área, com data e assinatura de um responsável técnico, contendo, dentre outras informações, atestado de que a vegetação a ser manejada foi plantada.

Quanto à atividade 01b, é importante ressaltar aspectos referentes ao enquadramento da vegetação como em estágio médio de regeneração, sendo que de acordo com a Resolução CONAMA $\mathrm{n}^{\circ} 33$ de 1994 [11], o estágio médio de regeneração é constituído por vegetação com fisionomia de porte arbustivo/arbóreo, com altura de até oito metros e diâmetro a altura do peito (DAP) de até $15 \mathrm{~cm}$, apresenta sub-bosque, diversidade biológica significativa, ocorrência de epífitas em maior número em relação ao estágio inicial e trepadeiras lenhosas quando presentes.

Tabela 1 - Atividades indicadas nos alvarás florestais emitidos no município de Condor-RS de 2015 a 2019.

\begin{tabular}{cc}
$\begin{array}{c}\text { N\%/COD } \\
\text { RAM }\end{array}$ & DESCRIÇÃO DA ATIVIDADE \\
\hline 01a & $\begin{array}{c}\text { Supressão de vegetação nativa em estágio inicial de regeneração } \\
\text { natural em propriedades com área de até } 25,0 \text { hectares (Área de } \\
\text { manejo até } 20.000 \mathrm{~m}^{2} \text { ) }\end{array}$ \\
\hline 01b & $\begin{array}{c}\text { Supressão de vegetação nativa em estágio médio de regeneração } \\
\text { natural em propriedades com área de até } 25,0 \text { hectares (Área de } \\
\text { manejo até } 20.000 \mathrm{~m}^{2} \text { ) }\end{array}$ \\
\hline 01c & $\begin{array}{c}\text { Supressão de vegetação nativa em estágio inicial de regeneração } \\
\text { natural em propriedades com área de até } 25,0 \text { hectares (área de } \\
\text { manejo superior a 20.000 m² ou àqueles que não se enquadram } \\
\text { como pequeno produtor rural). }\end{array}$ \\
\hline 02b & $\begin{array}{c}\text { Supressão de vegetação nativa em estágio médio de regeneração } \\
\text { natural em propriedades com área superior de } 25,0 \text { hectares }\end{array}$ \\
\hline
\end{tabular}

\begin{tabular}{|c|c|}
\hline 3 & $\begin{array}{l}\text { Exploração eventual de árvores nativas em propriedades com } \\
\text { área de até } 25 \text { hectares para uso na propriedade (até } 20 \text { metros } \\
\text { cúbicos de toras) }\end{array}$ \\
\hline 4 & $\begin{array}{c}\text { Exploração eventual de árvores nativas em propriedades com } \\
\text { área superior a } 25 \text { hectares para uso na propriedade (até } 20 \\
\text { metros cúbicos de toras) }\end{array}$ \\
\hline $05 a$ & $\begin{array}{c}\text { Corte de árvores nativas comprovadamente plantadas em } \\
\text { propriedades rurais com área de até } 25 \text { hectares (volume de toras } \\
\text { até } 50 \mathrm{~m}^{3} \text { ) }\end{array}$ \\
\hline 05b & $\begin{array}{c}\text { Corte de árvores nativas comprovadamente plantadas em } \\
\text { propriedades rurais com área de até } 25 \text { hectares (volume de toras } \\
\text { acima de } 50 \mathrm{~m}^{3} \text { ) }\end{array}$ \\
\hline $06 a$ & $\begin{array}{c}\text { Corte de árvores nativas comprovadamente plantadas em } \\
\text { propriedades rurais com área de superior a } 25 \text { hectares (volume } \\
\text { de toras até } 50 \mathrm{~m}^{3} \text { ) }\end{array}$ \\
\hline $07 \mathbf{a}$ & $\begin{array}{l}\text { Corte de árvores nativas comprovadamente plantadas em áreas } \\
\text { privadas situadas no perímetro urbano (até } 10 \text { árvores gerando } \\
\text { até } 20 \mathrm{~m}^{3} \text { ) }\end{array}$ \\
\hline $08 b$ & $\begin{array}{c}\text { Corte de árvores nativas comprovadamente plantadas em áreas } \\
\text { privadas situadas no perímetro urbano (acima de } 10 \text { árvores } \\
\text { gerando mais de } 20 \mathrm{~m}^{3} \text { ) }\end{array}$ \\
\hline 11 & $\begin{array}{l}\text { Manejo de árvores nativas por danos continuados ao patrimônio } \\
\text { ou causando risco de acidentes (até } 10 \text { árvores) }\end{array}$ \\
\hline 12 & $\begin{array}{l}\text { Manejo de árvores nativas por danos continuados ao patrimônio } \\
\text { ou causando risco de acidentes (acima de } 10 \text { árvores) }\end{array}$ \\
\hline
\end{tabular}

No período de estudo, foram emitidos 54 alvarás de serviços florestais, sendo nove em 2015, 14 em 2016, 20 em 2017, oito em 2018 e três em 2019 (Fig. 1). Brandt et al. [12], em levantamento das licenças emitidas no município de Roca SalesRS no período de janeiro de 2010 a julho de 2012, observaram que as licenças relacionadas ao extrativismo ou manutenção da vegetação nativa foram as mais demandadas, totalizando 134 licenças. Considerando o período avaliado, pode-se notar que em Roca Sales-RS o estudo apresentou uma média de 53,64 alvarás/ano, enquanto que no Município de Condor-RS essa média foi de 10,8 alvarás/ano. De acordo com os autores, o elevado número de alvarás no município de Roca Sales-RS pode estar relacionado a aplicação da Lei Federal $N^{\circ} 11.428 / 2006$, que prevê a manutenção da vegetação nativa no Domínio Mata Atlântica, com aos altos valores de multas e penas de reclusão em caso de descumprimento.

Battistela et al., [13] analisaram os benefícios gerados à população do município de Maximiliano de Almeida - RS através da municipalização das atividades de licenciamento ambiental e do histórico de autuações. O levantamento demonstrou que a maior parte das licenças emitidas pelo órgão municipal foram os alvarás florestais. Os autores ressaltam que a municipalização das licenças agilizou o processo de emissão, porém percebe-se que a população do município desconhece a sua obrigatoriedade, sendo que não trouxe uma redução no número de autuações. 


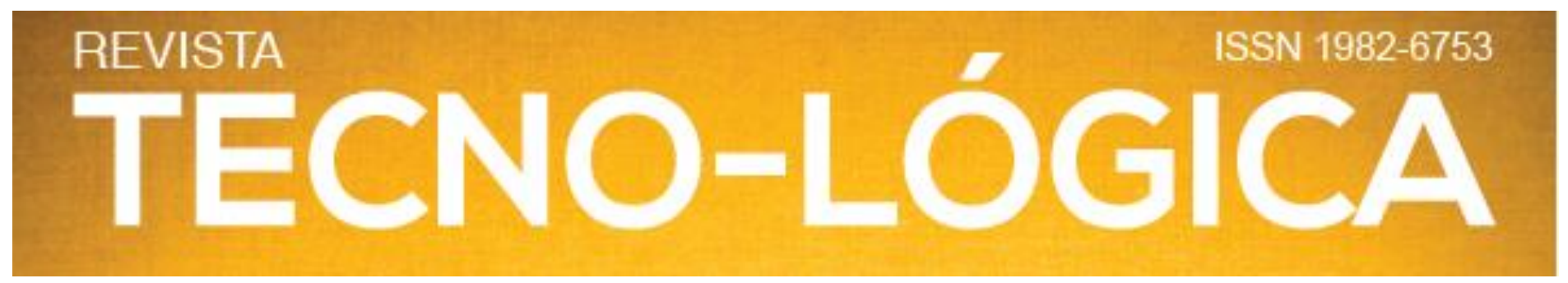

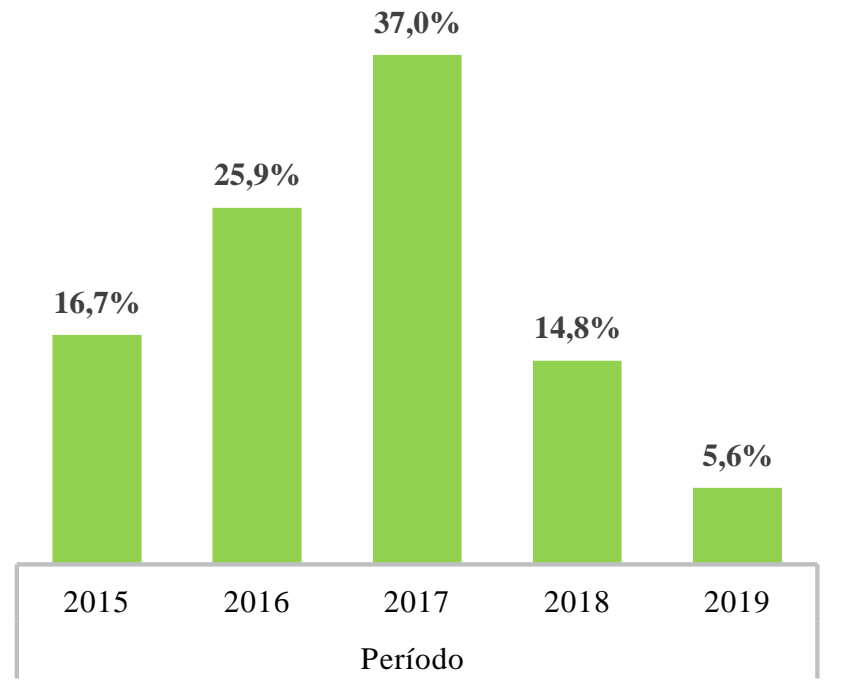

Figura 1 - Porcentagem de Alvarás emitidos por Ano.

Dentre os 54 alvarás emitidos no período, apenas $15 \%$ foram em perímetro urbano, já no perímetro rural foram 46 alvarás correspondendo a $85 \%$ (Fig. 2). Chiochetta e Tedesco [14], em estudo sobre o licenciamento ambiental municipal de 2 municípios do norte do RS, no período de 2010 a 2015, verificaram que no município de porte médio (197.206 habitantes) 82,3\% das licenças foram para o perímetro urbano, diferentemente do evidenciado no município de pequeno porte (1.645 habitantes) onde $68,4 \%$ das licenças foram para o perímetro rural, corroborando o resultado do município de Condor-RS, também considerado de pequeno porte.

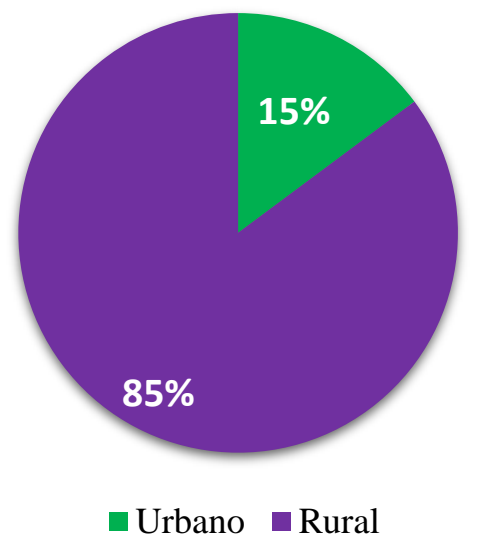

Figura 2 - Percentual de alvarás florestais emitidos no município de Condor-RS entre 2015 e 2019 em área urbana e rural.
Na figura 3 pode-se observar as atividades indicadas nos alvarás do perímetro urbano e rural, com o respectivo número de alvarás emitidos por atividade no período.

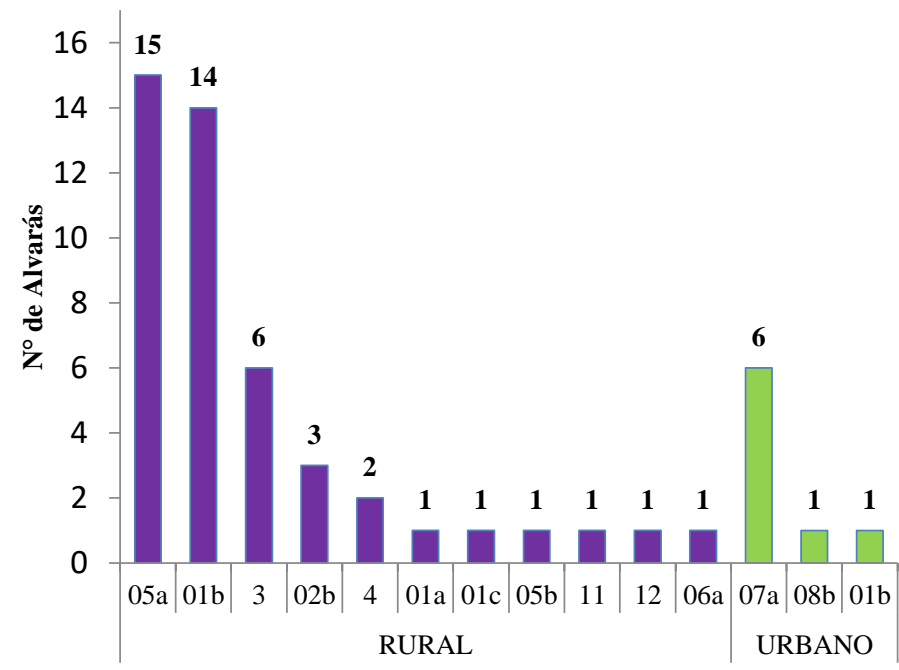

Figura 3. Número de alvarás florestais emitidos no município de Condor-RS entre 2015 e 2019 em área urbana e rural por atividade.

No perímetro rural as atividades com mais indicações nos alvarás foram a 05a (Corte de árvores nativas comprovadamente plantadas em propriedades rurais com área de até 25 hectares), com 15 alvarás $(32,61 \%$ ) e a 01b (Supressão de vegetação nativa em estágio médio de regeneração natural em propriedades com área de até 25,0 hectares), com 14 alvarás (30,43\%). Considerando as duas atividades mais solicitadas têm-se um percentual de $63,05 \%$ do total de alvarás emitidos no perímetro rural.

Georgin et al. [15], realizou estudo com o objetivo de analisar as modalidades de licenciamentos emitidas com maior frequência pelas prefeituras de quatro municípios da região norte do estado do Rio Grande do Sul. Os autores concluíram que as modalidades de licenciamento mais frequentes ocorrem em áreas rurais, com demandas para a retirada de alguns indivíduos arbóreos para usos na própria propriedade. No entanto, os autores observaram que dentre os serviços ambientais mais frequentes de uma empresa local de consultoria estavam os Projetos de Recuperação de Áreas Degradadas (PRAD), justificado pelo fato dos produtores sofrerem autuação pela retirada de vegetação natural para o avanço da agricultura sem o devido licenciamento.

Além das atividades inerentes ao setor agrícola, atividades desenvolvidas em área urbana também requerem o 


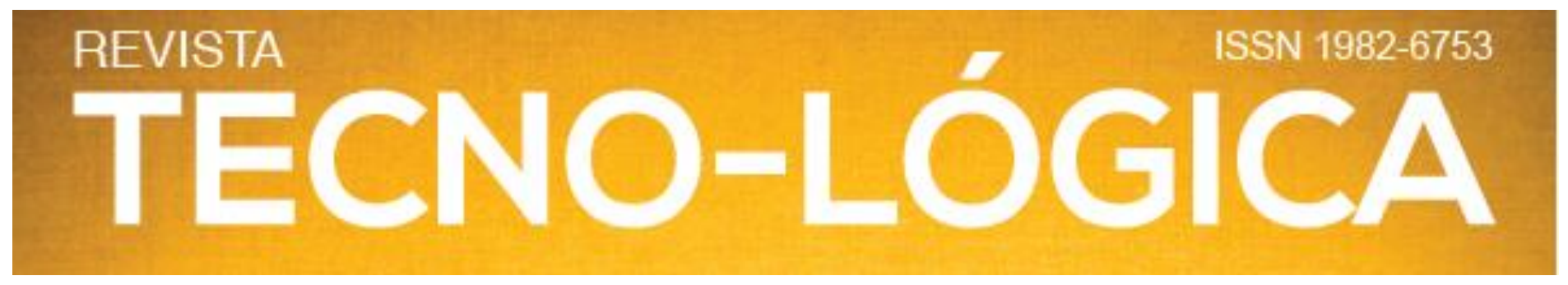

manejo do meio ambiente. Em estudo realizado por Antunes [16], com o objetivo de avaliar o impacto ambiental na vegetação nativa e em áreas de preservação permanente (APP) em loteamentos construídos no perímetro urbano do município de Erechim-RS, constatou-se que o principal impacto registrado foi a supressão de vegetação nativa.

As atividades destacadas nos alvarás de perímetro urbano foram a 07a (Corte de árvores nativas comprovadamente plantadas em áreas privadas situadas no perímetro urbano) com 6 alvarás emitidos, representando $75 \%$ dos alvarás emitidos em perímetro urbano. Os demais alvarás apresentaram as respectivas atividades, 01b (Supressão de vegetação nativa em estágio médio de regeneração natural em propriedades com área de até 25,0 hectares) e 08 b (Corte de árvores nativas comprovadamente plantadas em áreas privadas situadas no perímetro urbano), totalizando 8 alvarás (Figura 3).

Ao analisar o total licenciado no município, em volume de toras, observou-se um total de $369,69 \mathrm{~m}^{3}$ de toras no período. O perímetro rural respondeu a quase 9 vezes mais volume de madeira extraída do que no perímetro urbano, totalizando 332,21 $\mathrm{m}^{3}(89,86 \%)$, enquanto que no perímetro urbano tem-se um volume de $37,48 \mathrm{~m}^{3}(10,14 \%)$. Na figura 4 pode-se observar a distribuição do volume de toras licenciado por ano, com destaque para os anos de 2017 e 2018, com respectivamente $37,1 \%$ e $27,3 \%$.

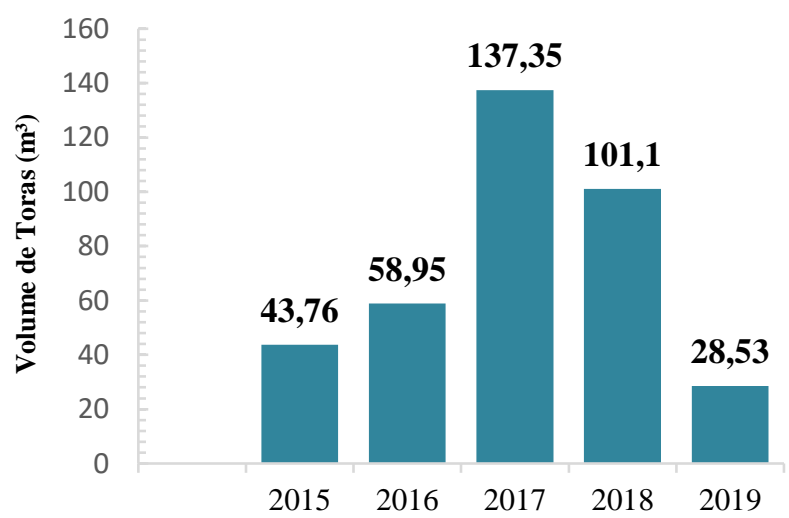

Figura 4 - Volume de toras licenciado no município de Condor-RS entre 2015 e 2019.

Quanto às atividades que trazem seu total licenciado em $\mathrm{m}^{2}$, os alvarás apresentaram um total de $187.642,00 \mathrm{~m}^{2}$ (18,8 ha). No perímetro urbano, o alvará enquadrado na atividade $01 \mathrm{~b}$, apresentou um total de $10.000 \mathrm{~m}^{2}$, correspondendo a 5,33\% da área total licenciada no período. Já no perímetro rural, contabilizou-se uma área de 177.642,00 m² (17,8 ha), correspondendo a 94,67\% da área total. Na figura 5 pode-se observar a distribuição da área total licenciada por ano, com destaque para os anos de 2017 e 2016, com respectivamente $43,31 \%$ e $39,79 \%$.

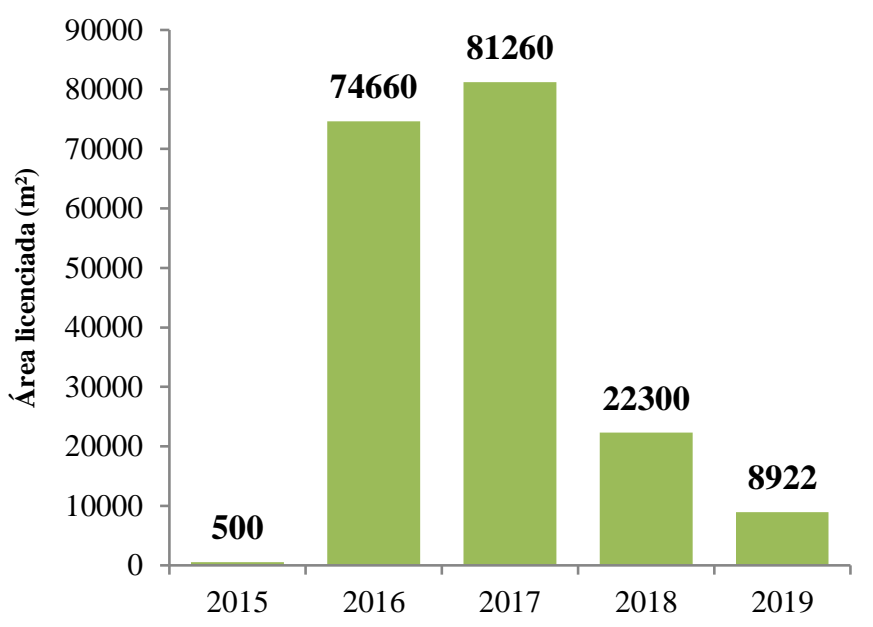

Figura 5 - Área total a ser manejada com licenciamento no município de CondorRS entre 2015 e 2019.

Quanto ao número de indivíduos suprimidos por ano, nota-se na figura 6 que os anos de 2017, 2018 e 2015 correspondem respectivamente a $38,6 \%, 23,4 \%$ e $21,3 \%$ dos 376 indivíduos suprimidos no período. No perímetro urbano foram suprimidos 59 indivíduos (15,69\%), enquanto que no perímetro rural foram suprimidos 317 indivíduos $(84,31 \%)$.

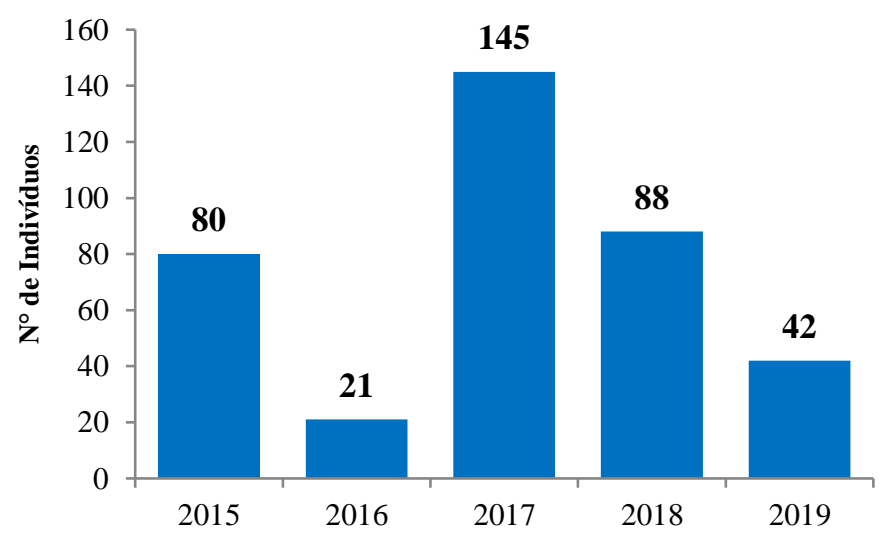

Figura 6 - Número de indivíduos por ano no município de Condor-RS

Segundo o acervo da Flora Digital do Rio Grande do Sul e de Santa Catarina, e a lista vermelha do Centro Nacional de Conservação da Flora foram elencadas as espécies que apresentam algum grau de ameaça, no âmbito estadual e/ou nacional, com o respectivo número de indivíduos suprimidos no período avaliado 


\section{REVISTA}

(quadro 1). Dos 376 indivíduos, identificou-se um total de 44 espécies as quais pertencem a 19 famílias distintas. As famílias Fabaceae e Lauraceae apresentaram o maior número de espécies suprimidas, com respectivamente $27,3 \%$ e $11,4 \%$.

\begin{tabular}{|c|c|c|c|c|c|}
\hline \multirow{2}{*}{$\begin{array}{c}\text { Nome } \\
\text { Científico }\end{array}$} & \multirow{2}{*}{ Família } & \multirow{2}{*}{$\begin{array}{c}\text { Nome } \\
\text { Comum }\end{array}$} & \multicolumn{2}{|c|}{ Grau de Ameaça } & \multirow{2}{*}{$\begin{array}{c}\mathrm{N}^{0} \mathrm{de} \\
\text { Indivíduos } \\
\text { Suprimidos } \\
\end{array}$} \\
\hline & & & Estadual & Nacional & \\
\hline $\begin{array}{l}\text { Nectandra } \\
\text { grandiflora }\end{array}$ & Lauraceae & $\begin{array}{c}\text { canela } \\
\text { amarela, } \\
\text { canelafedida }\end{array}$ & $\begin{array}{c}\text { Vulnerável } \\
\text { (VU) }\end{array}$ & \begin{tabular}{|c|} 
Menos \\
preocupant \\
$\mathrm{e}(\mathrm{LC})$ \\
\end{tabular} & 4 \\
\hline $\begin{array}{c}\text { Ocotea } \\
\text { puberula }\end{array}$ & Lauraceae & canelagguaicá & & $\begin{array}{c}\text { Quase } \\
\text { ameaçada } \\
\text { (NT) }\end{array}$ & 2 \\
\hline $\begin{array}{c}\text { Araucaria } \\
\text { angustifolia }\end{array}$ & Araucariaceae & $\begin{array}{c}\text { pinheiro-do- } \\
\text { paraná } \\
\text { araucária, } \\
\text { pinheiro- } \\
\text { brasileiro } \\
\end{array}$ & $\begin{array}{c}\text { Vulnerável } \\
\text { (VU) }\end{array}$ & $\begin{array}{c}\text { Emperigo } \\
\text { (EN) }\end{array}$ & 148 \\
\hline $\begin{array}{c}\text { Gleditsia } \\
\text { amorphoides }\end{array}$ & Fabaceae & $\begin{array}{l}\text { coronilha, } \\
\text { sucará, } \\
\text { açucará }\end{array}$ & $\begin{array}{c}\text { Em Perigo } \\
\text { (EN) }\end{array}$ & $\begin{array}{c}\text { Vulnerável } \\
\text { (VU) }\end{array}$ & 2 \\
\hline $\begin{array}{c}\text { Myrocarpus } \\
\text { frondosus }\end{array}$ & Fabaceae & cabreúva & $\begin{array}{c}\text { Vulnerável } \\
\text { (VU) }\end{array}$ & \begin{tabular}{|c|} 
Menos \\
preocupant \\
$\mathrm{e}(\mathrm{LC})$ \\
\end{tabular} & 4 \\
\hline $\begin{array}{l}\text { Cedrela } \\
\text { fissilis }\end{array}$ & Meliaceae & Cedro & & $\begin{array}{c}\text { Vulnerável } \\
\text { (VU) }\end{array}$ & 7 \\
\hline $\begin{array}{c}\text { Butia } \\
\text { eriospatha }\end{array}$ & Arecaceae & $\begin{array}{l}\text { butiazeiro, } \\
\text { butiá }\end{array}$ & $\begin{array}{c}\text { Em Perigo } \\
\text { (EN) }\end{array}$ & \begin{tabular}{|c|} 
Vulnerável \\
(VU)
\end{tabular} & 13 \\
\hline
\end{tabular}

Quadro 1 - Grau de ameaça por espécies e número de indivíduos suprimidos no município de Condor-RS de 2015 a 2019.

A figura 7 demostra o número de indivíduos suprimidos por espécies, sendo representadas apenas as espécies que tiveram um número representativo de supressão nos cinco anos avaliados.

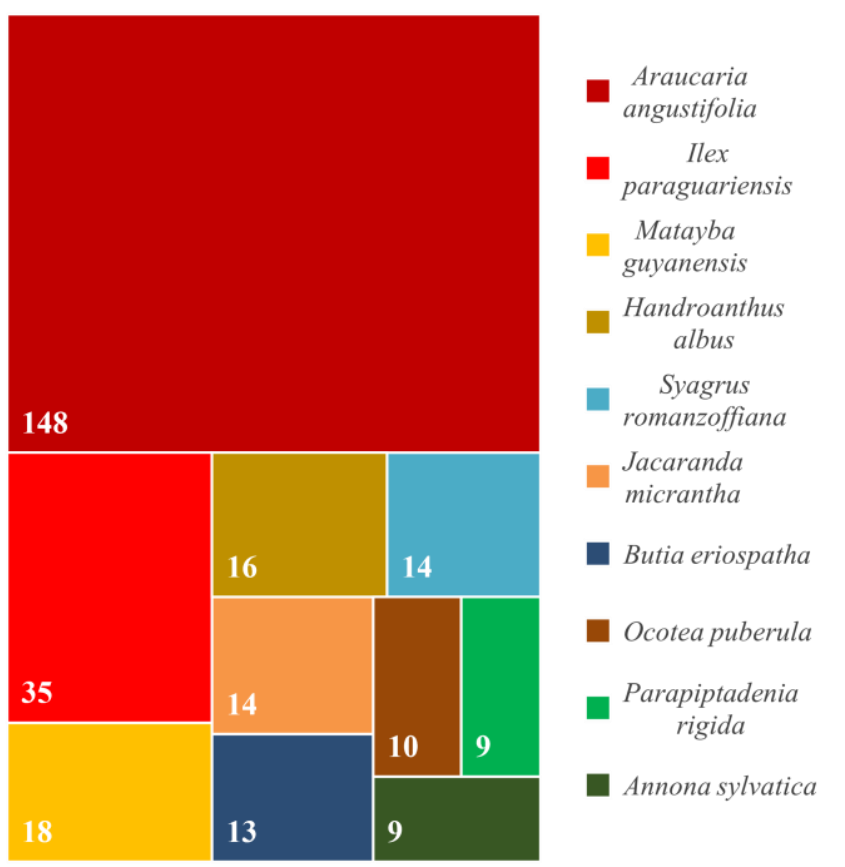

Figura 7 - Número de indivíduos suprimidos por espécies no município de CondorRS entre 2015 e 2019.

Cabe ressaltar que algumas espécies foram suprimidas apenas em um ano, como no caso do Butia eriospatha, Annona sylvatica, Handroanthus albus, Jacaranda micrantha, Ilex paraguariensis e Matayba guyanensis. A figura 8 apresenta as espécies que ocorreram no mínimo em 3 anos.

Quanto ao perímetro urbano, a figura 9 traz o percentual de indivíduos por espécie considerando os 59 indivíduos que foram suprimidos no período, com destaque para a espécie Araucaria angustifolia com 25,4\%, Butia eriospatha, com $22 \%$ e Annona sylvatica com 15,2\%. No perímetro rural, dos 317 indivíduos suprimidos, a Araucaria angustifolia aparece novamente em destaque, com 41,96\% dos indivíduos, seguida com vasta diferença da Ilex paraguaiensis com 11,04\% e da Matayba guyanensis com 5,68\%, conforme observa-se na figura 10. 


\section{REVISTA}

ISSN 1982-6753
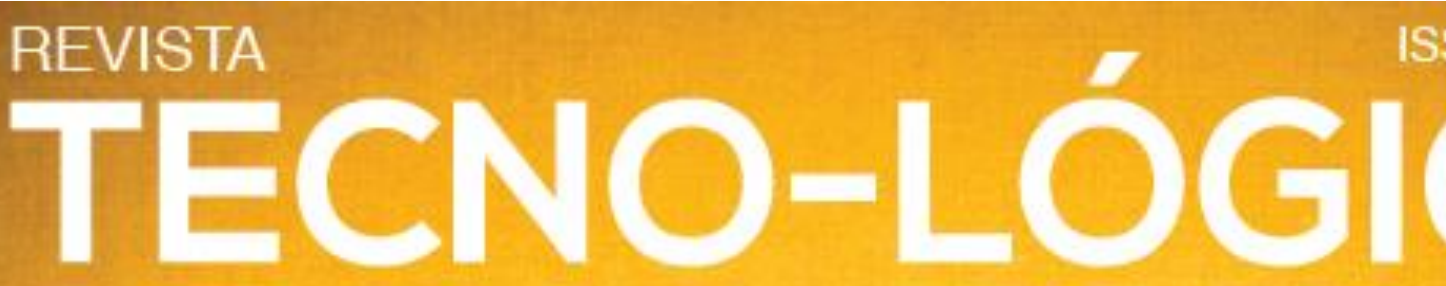

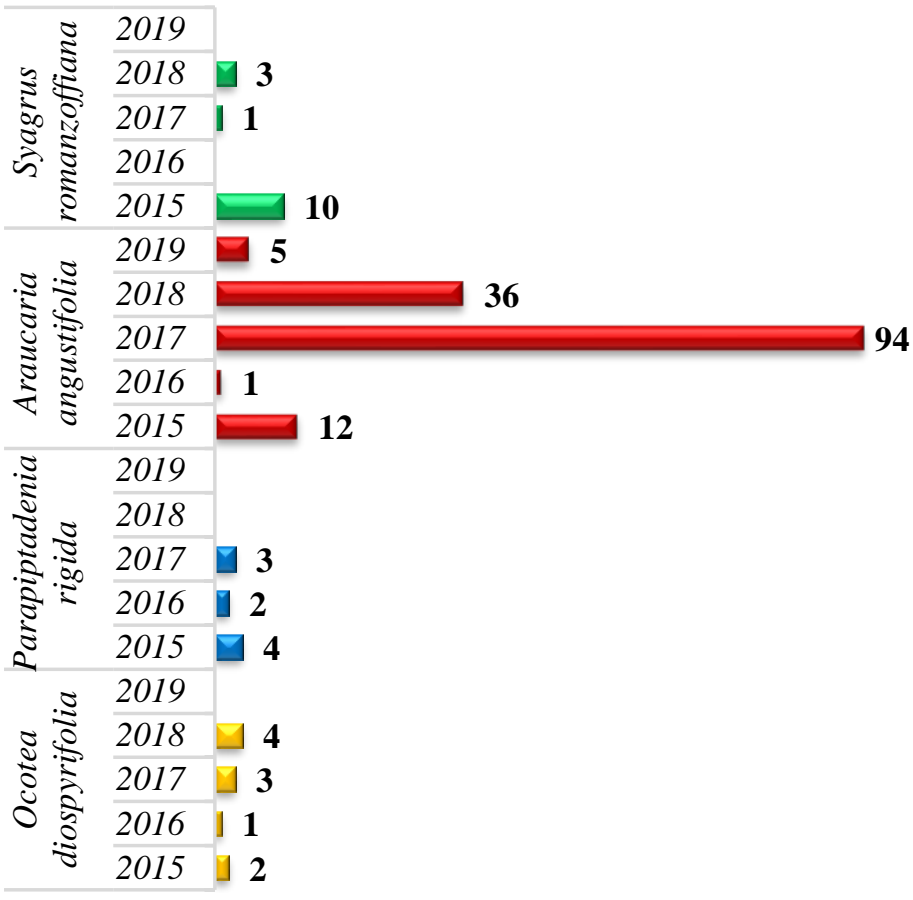

Figura 8 - Espécies com maior ocorrência de supressão por ano e número de indivíduos suprimidos no município de Condor-RS.

Observa-se que a Araucaria angustifolia conhecida também por pinheiro, pinheiro-do-paraná, araucária e pinheirobrasileiro, é a mais suprimida, tanto no perímetro urbano como no rural, a mesma possui seu grau de ameaça estadual como "Vulnerável" (VU), e o grau de ameaça nacional como "em perigo" (EN). Trata-se de uma espécie madeireira de grande valor comercial, que mesmo sendo ameaçada ainda sofre com a exploração madeireira, apesar de ser protegida por lei.
Araucaria angustifolia (Araucaria)

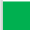

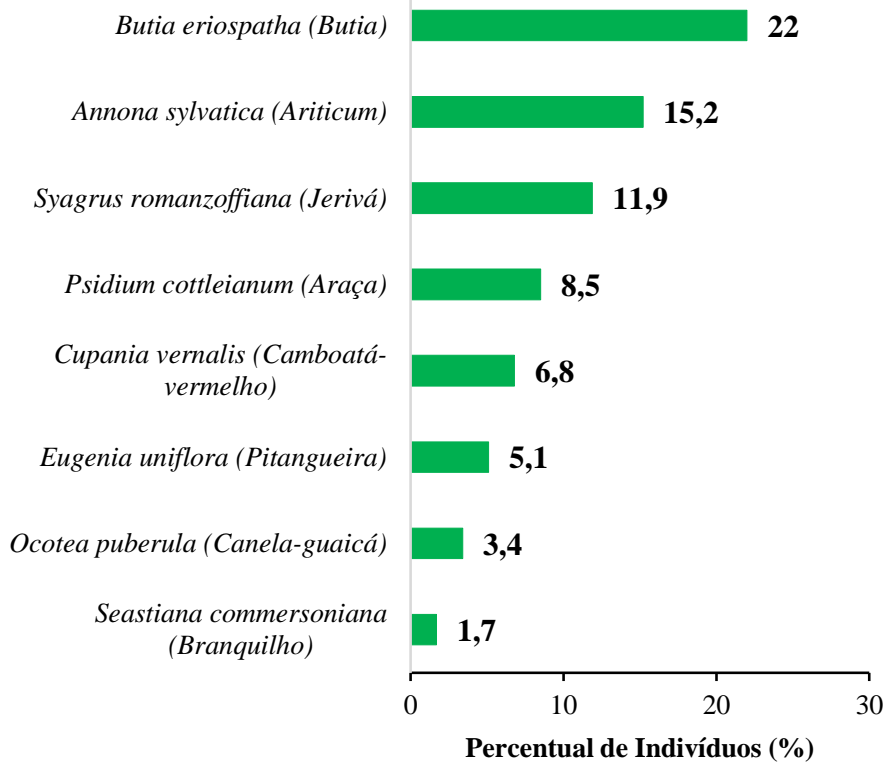

Figura 9 - Espécies e percentual de indivíduos suprimidos no perímetro urbano no município de Condor-RS entre 2015 e 2019.

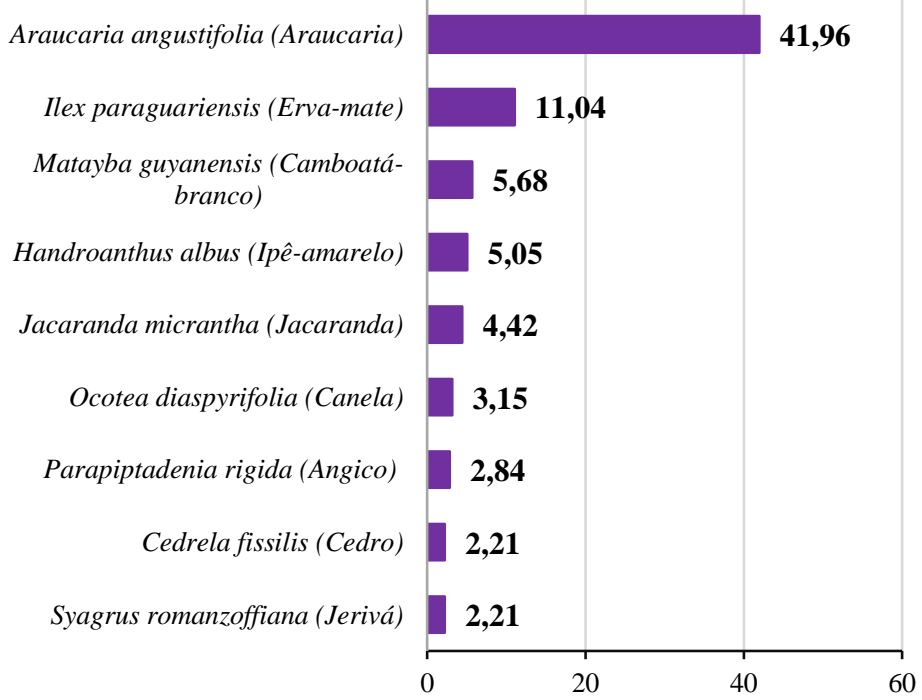

Percentual de Indivíduos (\%) 


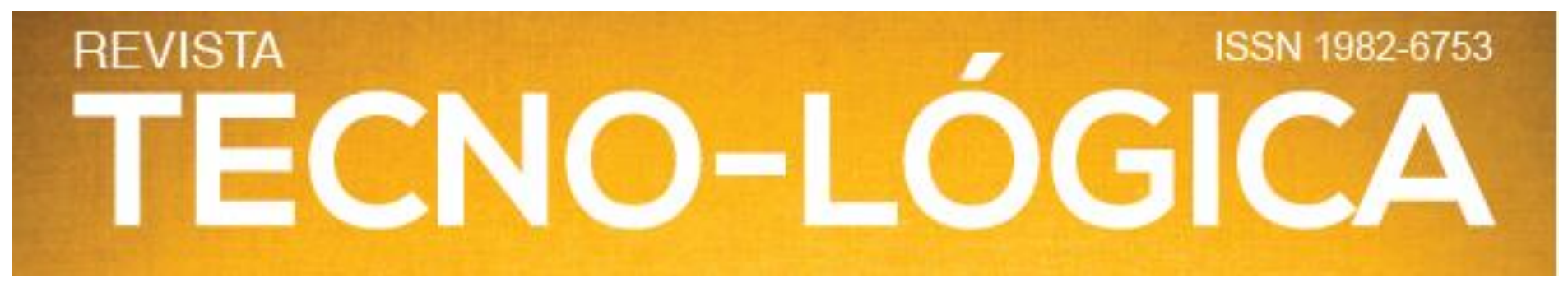

Figura 10 - Espécies e percentual de indivíduos suprimidos no perímetro rural no município de Condor-RS entre 2015 e 2019.

Em destaque também Butia eriospatha da família Arecaceae, conhecido também por butiazeiro ou butiá, o qual tem seu grau de ameaça a nível estadual como EN e a nível nacional como VU. Butia eriospatha ocorre nas Formações Campestres de altitude da Região Sul do Brasil, a espécie está sujeita a um rápido declínio na extensão e qualidade do seu habitat ao longo de praticamente toda a sua distribuição, devido à expansão de atividades agropecuárias. É possível suspeitar que, em áreas intensamente urbanizadas, como a cidade de Curitiba, a espécie tenha sido extinta localmente [9].

Entre as espécies suprimidas no perímetro urbano, com um percentual baixo de supressão, mas classificada a nível nacional como "quase ameaçada" (NT) está Ocotea puberula conhecida também por canela-guaicá. Muito expressiva em área alterada, comportando-se como pioneira, ocorre em todas as regiões, apesar de amplamente distribuída e de crescimento rápido, seus frutos são frequentemente atacados pelo fungo Botvyoconiepallida Syd, o que reduz a produção de sementes viáveis, o que compromete o potencial genético da espécie comprometido. Adicionalmente, o extrativismo pode se tornar uma ameaça em um futuro próximo [9].

Cedrela fissilis da família Meliaceae, conhecida também como cedro está entre as espécies suprimidas no perímetro rural, apresentando um grau de ameaça a nível nacional como vulnerável (VU). Essa espécie é amplamente distribuída em todo Brasil, possui madeira leve a moderadamente pesada, macia ao corte, com boa durabilidade ao ambiente seco, fácil de trabalhar, largamente usada em compensados, contra placas, na construção civil, naval e aeronáutica, na confecção de pequenas caixas, lápis e instrumentos musicais, possui óleo essencial que aparentemente a protege do ataque de cupins, portanto vem sofrendo com a exploração madeireira, tendo muitas das subpopulações extintas e seus habitats completamente degradados[9].

Ao analisar a reposição florestal demonstrada nos alvarás, percebe-se que apenas $50 \%$ destas apresentaram indicação de reposição, sendo indicado um total de 9.185 mudas para reposição no período avaliado. Cabe salientar que nos documentos avaliados não foram encontrados as espécies que deveriam ser plantadas, indicando somente o local de plantio.

Observou-se também que nos oito alvarás emitidos no perímetro urbano, apenas um consta reposição florestal. O alvará a qual consta a reposição está enquadrado na atividade " $01 b$ ", onde o mesmo indicava uma reposição de 920 mudas. Assim, percebesse que, a reposição florestal está diretamente ligada a atividade enquadrada no alvará, observando que as atividades que constam reposição são: $01 b, 02 b, 3,4$ e 12; entende-se que as demais atividades, 01a, 01c, 05a, 05b, 06a, 07a, 08b e 11 não necessitam reposição florestal.

Em pesquisa de campo realizada por Brun e Egert [17], avaliando Termos de Ajustamento de Conduta firmados entre o órgão fiscalizador e o infrator, em dez casos de município do Norte do estado do Rio Grande do Sul, entre os anos de 2014 e 2015, concluíram que houve uma compensação de 49,25\% com relação a área devastada, considerando este percentual incipiente.

Outro ponto levantado na pesquisa foi a qualificação técnica do responsável técnico de cada alvará, no qual constatouse cinco alvarás sob responsabilidade de engenheiros agrônomos e 44 sob responsabilidade de técnicos agrícolas, ficando cinco alvarás sem identificação de responsável técnico.

\section{Conclusões}

Fundamentalmente, com base no presente estudo, destaca-se a importância do licenciamento florestal para gestão ambiental no âmbito municipal, o qual foi capaz de originar dados consistentes para discussão e avaliação das espécies suprimidas no perímetro urbano e rural do município em questão.

$\mathrm{O}$ estudo demonstrou uma intensa exploração de poucas famílias, sendo as famílias Fabaceae e Lauraceae as mais suprimidas, representando 38,4\% das 19 famílias. Avaliando a supressão por indivíduos, Araucaria angustifolia foi a espécie que teve maior número de indivíduos suprimidos, sendo que a mesma apresenta um grau de ameaça considerável no âmbito nacional e estadual. Observa-se também que sete espécies foram suprimidas mesmo contendo algum grau de ameaça, tanto a nível estadual como nacional.

Portanto, nota-se que é de extrema importância, o departamento de meio ambiente do município de Condor-RS, tomar medidas de conscientização sobre a importância do licenciamento florestal, sobre a supressão de espécies as quais estão classificadas com algum grau de risco, inibir essas supressões, e ainda, direcionar para que as medidas de mitigação priorizem o replantio dessas espécies.

\section{EVALUATION OF THE SUPPRESSION OF NATIVE VEGETATION IN THE MUNICIPALITY OF CONDOR, RIO GRANDE DO SUL}

ABSTRACT: Human interventions in native forest areas, in urban areas and in rural areas are more and more frequent. Taking into account the size of the intervention, the associated environmental impacts may cause great damage to the biotic and abiotic environment. Federal Law N $\mathrm{N}^{\circ}$ 6.938/81, establishing the National Environment Policy, brings as one of its most important 


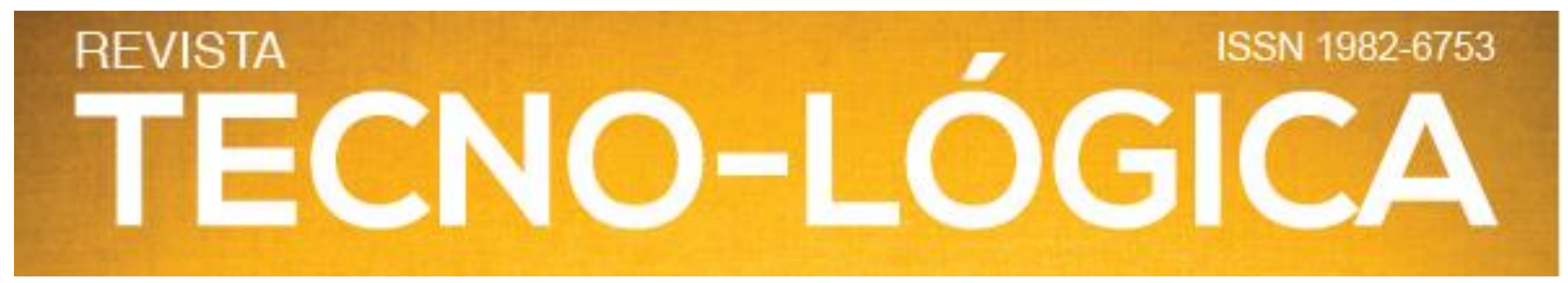

instruments, environmental licensing. Among the various types of licensing, there is forest licensing which is the instrument of the State's forest policy, comprising services provided by the competent state or municipal environmental agency. CONSEMA Resolution 372/2018 defines that for local impact activities, the agency responsible for licensing is the municipality. Rio Grande do Sul officially has 804 species of its native flora threatened with extinction. In this way, the importance of identifying which species of flora are suffering the greatest suppression is perceived, considering the forest licensing within the scope of the municipality of Condor-RS, as well as identifying aspects related to the management location (urban or rural), forest replacement proposal, and training of the technicians responsible for the environmental licensing Project. The data were extracted from forest licenses issued by the environmental licensing agency in the municipality of Condor-RS, through research and analysis of forest permits granted in the last 5 years (2015 to 2019). The study demonstrated an intense exploitation of few families, the Fabaceae and Lauraceae families being the most suppressed. The largest number of suppressed owners belongs to the species Araucaria angustifolia.

Keywords: Deforestation. Araucaria angustifólia. Forestry Licensing. Environmental management.

\section{Referências}

[1] MORAES, L. C.; Licenciamento Ambiental: do programático ao pragmático, Soc.\& Nat., Vol. 28, n. 2, p. 215-226, 2016.

[2] CHIAPPETI, I. S.; Programas e projetos. Mata Atlântica, 2009. Disponível em: <http://www.fepam.rs.gov.br/programas/kfw.asp.> Acesso em: 03 de Nov. de 2020

[3] CONDOR. Plano Municipal de Desenvolvimento Rural de Condor - PMDR. Condor-RS, 2009. Disponível em: <https://cespro.com.br/7412/2016_L2351.pdf.> Acesso em: 03 de Nov. de 2020.

[4] GURGEL JR, F. J. Licenciamento Ambiental: Discutindo Conceitos, AS\&T, v. 2, n. 2, p.19-27, 2014.

[5] Rio Grande do Sul. Manejo e corte de vegetação nativa, portal de licenciamento ambiental. Disponível em: $<\mathrm{http}: / / w w w . l i c e n c i a m e n t o a m b i e n t a l . r s . g o v . b r / m a n e j o-$ e-corte-de-vegetacao> Acesso em: 10 de Nov. de 2020

[6] GOVERNO DO ESTADO DO RIO GRANDE DO SUL. Resolução $n^{\circ} 372$, de 22 de fevereiro de 2018. Conselho Estadual do Meio Ambiente (COSNEMA). Dispõe sobre os empreendimentos e atividades utilizadores de recursos ambientais, efetiva ou potencialmente poluidores ou capazes, sob qualquer forma, de causar degradação ambiental, passíveis de licenciamento ambiental no Estado do Rio Grande do Sul, destacando os de impacto de âmbito local para o exercício da competência municipal no licenciamento ambiental, 2018. Disponível em: <https://www.sema.rs.gov.br/upload/arquivos/201803/15120855-372-2018atividades-licenciavies-revisao-288.pdf>. Acesso em: 26 Nov. 2020.

[7] SEMA - Secretaria Estadual do Meio Ambiente do Rio Grande do Sul. Táxons da flora nativa do Estado Rio Grande do Sul ameaçadas de extinção (categorias: Criticamente em Perigo - CR, Em perigo - EM e Vulnerável - VU). Porto Alegre, $2014 . \quad$ Disponível em: http://www.fzb.rs.gov.br/upload/20141208161010anexo_i_taxons_da_flora_nativ a_do_estado_rio_grande_do_sul_ameacadas_de_extincao_1_.pdf. Acesso em: 03 de Dez. de 2020

[8] Projeto Flora Digital. O projeto é coordenado por Eduardo L. Hettwer Giehl. Disponível em: < https://floradigital.ufsc.br/index.php> Acesso em: 03 de Dez. de 2020.

[9] CNCFlora - Centro Nacional de Conservação da Flora. Instituto de Pesquisas Jardim Botânico do Rio de Janeiro. Disponível em: <http://cncflora.jbrj.gov.br/portal/> Acesso em: 03 de Dez. de 2020.

[10] GIL, A. C. Como elaborar projetos de pesquisa. 4. ed. São Paulo: Atlas, 2002. $176 \mathrm{p}$

[11] CONAMA. Resolução CONAMA N ${ }^{\circ} 33$, de 7 de dezembro de 1994. Conselho Nacional do Meio Ambiente (CONAMA). Define estágios sucessionais das formações vegetais que ocorrem na região da Mata Atlântica do Estado do Rio Grande do Sul, visando viabilizar critérios, normas e procedimentos para o manejo, utilização racional e conservação da vegetação natural. Disponível em: <https://sema.rs.gov.br/upload/arquivos/201612/02142051-resolucao-conama-n33.pdf>. Acesso em: 09 Fev. 2021

[12] BRANDT, F.; SALVATORI, R. U.; REMPEL, C.; BICA, J. B.; STROHSCHOEN, A. A. G. O desafio do licenciamento ambiental no município de Roca Sales, Rio Grande do Sul, Brasil. Revista de Ciências Ambientais - RCA, Canoas, v. 7, n. 2. 2013.

[13] BATTISTELLA, F.; PFÜLLER, E. E.; PORSCH, M. R. M. H.; SILVA, R. S.; PRADO, G. R. Licenciamento Ambiental municipalizado: estudo de caso do departamento municipal de Maximiliano de Almeida/RS. RAMVI, Getúlio Vargas, v. 02, n. 04.Jul-Dez. 2015.

[14] CHIOCHETTA, B.; TEDESCO, C. D. Licenciamento Ambiental Municipal e minimização dos impactos em dois municípios do norte do RS. Revista Gestão \& Sustentabilidade Ambiental, Florianópolis, v. 7, n. 2, p.411-425, abr/jun. 2018.

[15] GEORGIN, J.; LAZZARI, L.; CAMPONOGARA, A.; ELOY, J. B.; PAULI, E. As modalidades mais frequentes de licenciamento realizadas em municípios da região norte do Rio Grande do Sul. REMOA. V.14, n.1, 136-143, jan-abr. 2015.

[16] ANTUNES, L. M. Impacto Ambiental nos loteamentos na área de expansão do perímetro urbano no município de Erechim, Rio Grande do Sul, Brasil. 2018. 59 f. Monografia (Pós Graduação em Gestão Ambiental em Municípios) - Polo UAB Concórdia-SC, Universidade Tecnológica Federal do Paraná -UTFPR. Medianeira. 2018.

[17] BRUN, L. I.; EGERT, R. Pesquisa de campo sobre a (in)efetividade da compensação entre a área degradada e a área regenerada no termo de ajustamento de conduta (TAC). Revista Jurídica Direito e Cidadania na Sociedade Contemporânea. v. 2, n. 1, 150-162. 2018. 